NOTA DE PESQUISA

\title{
DESENVOLVIMENTO DOS FUNGOS Metarhizium anisopliae (METSCHNIKOFF, 1879) SOROKIN, 1883 E Beauveria bassiana (BALSAMO) VUILLEMIN, 1912 SOBRE Ctenocephalides felis felis (BOUCHÉ, 1835)
}

\author{
DENISE R. DE MELO ${ }^{1}$; GERALDO B. DA CRUZ²; ROSANA C.S. REIS ${ }^{3}$; VÂNIA R.E.P. BITTENCOURT ${ }^{4}$
}

\begin{abstract}
MELO, D.R. DE; CRUZ, G.B. DA; REIS, R.C.S.; BITTENCOURT, V.R.E.P. [Development of the fungi Metarhizium anisopliae (Metschnikoff, 1879) Sorokin, 1883 and Beauveria bassiana (Balsamo) Vuillemin, 1912 on the Ctenophephalides felis felis (Bouché, 1835)]. Desenvolvimento dos fungos Metarhizium anisopliae (Metschnikoff, 1879) Sorokin, 1883 e Beauveria bassiana (Balsamo) Vuillemin, 1912 sobre Ctenocephalides felis felis (Bouché,1835). Revista Brasileira de Parasitologia Veterinária, v. 16, n. 3, p. 166-170, 2007. Departamento de Parasitologia Animal, Instituto de Veterinária, Universidade Federal Rural do Rio de Janeiro, BR 465, Km 7, Seropédica, RJ, 23890-000, Brazil. E-MAIL: vaniabit@ufrrj.br

The flea Ctenocephalides felis felis is a parasite that causes allergic dermatitis and also may transmit etiologic agents to domestic animals and humans. This study investigated by scanning electron microscopy the development of entomopathogenic fungi on flea cuticle. Fleas were exposed to conidia $\left(10^{8} \mathrm{ml}^{-1}\right)$ of Metarhizium anisopliae (isolate 959) or Beauveria bassiana (isolate 986). Following standard protocols for electron microscopy, the specimens were prepared 2, 15, 26 and $96 \mathrm{~h}$ after infection. The micrography revealed that $2 \mathrm{~h}$ after fungus exposure, conidia attachments encompassed the entire flea cuticle, especially on abdominal intersegmental membranes. The emergence of germ tubes and appressoria formation occurred at $15 \mathrm{~h}$, thickening and branching of hyphae on the flea cuticle was noted at $26 \mathrm{~h}$. Therefore, both of these fungal isolates were able to develop on cuticular surfaces of C.f. felis.
\end{abstract}

KEYWORDS: Scanning electron microscopy, entomopathogenic fungus, flea.

\section{RESUMO}

A pulga Ctenocephalides felis felis é um parasita causador dermatites alérgicas e também pode transmitir diversos agentes etiológicos aos animais domésticos e aos homens. O objetivo deste trabalho foi verificar o desenvolvimento do fungo sobre a cutícula da pulga, através da microscopia eletrônica de varredura. Os isolados fúngicos testados foram o Metarhizium anisopliae 959 e Beauveria bassiana 986, ambos na concentração $10^{8}$ conídios/ml. Após a exposição dos

${ }^{1}$ Curso de Pós-Graduação em Ciências Veterinárias (CPGCV), Universidade Federal Rural do Rio de Janeiro (UFRRJ), Km 7 da BR 465, Seropédica, RJ 23890-000. Bolsista CAPES.

${ }^{2}$ EMBRAPA Agrobiologia, Seropédica, RJ 23890-000.

${ }^{3}$ Departamento de Zootecnia, Universidade Federal de Roraima (UFRR), Km 12 da BR 174, Boa Vista, RR 69300-000.

${ }^{4}$ Departamento de Parasitologia Animal, Instituto de Veterinária, UFRRJ. Bolsista CNPq. E-mail: vaniabit@ufrrj.br isolados fúngicos no período de duas, 15, 26 e 96 horas , o material foi processado para a microscopia eletrônica de varredura. Com a obtenção das micrografias, pode-se observar que com 2 horas após exposição aos fungos, os conídios estavam aderidos por toda a cutícula, situando-se preferencialmente nas membranas intersegmentais do abdome. Com 15 horas observou-se a formação do tubo de germinação e a cabeça do apressório e após 26 horas foi possível observar as ramificações e o engrossamento das hifas sobre a cutícula das pulgas. Os resultados indicam que os fungos testados foram capazes de se desenvolver sobre a cutícula de C.f. felis.

PALAVRAS-CHAVE: Microscopia eletrônica de varredura, fungos entomopatogênicos, pulga.

As pulgas são ectoparasitos de importância epidemiológica que podem transmitir agentes patogênicos para o homem e 
para animais domésticos, principalmente quando se associa que cães e gatos são animais de companhia que estabeleceram um estreito convívio com o homem, freqüentando sua moradia ou habitando lugares muito próximos a estas. Uma vez sobre o hospedeiro, a pulga inicia a hematofagia, sua picada pode causar desconforto e manifestação de dermatites alérgicas, como também transmitir diversos agentes etiológicos aos animais domésticos e aos homens (DRYDEN; BROCE, 1993; LINARDI; GUIMARÃES, 2000).

Até recentemente, o controle químico de pulgas no animal era realizado, quase que de forma exclusiva. Entretanto, a rápida adaptação das pulgas a alguns princípios ativos, e sua aplicação feita de forma desordenada, conduziram ao aparecimento de populações de pulgas resistentes. O desenvolvimento de resistência aos produtos químicos é o principal fator de falha no controle destes insetos. Atualmente, há poucos inseticidas para se escolher em um programa de controle. Além disto, o seu custo é muito elevado o que, aliado aos outros fatores já citados, favorece ao aumento do interesse pelo controle biológico (BOSSARD et al., 1998; DRYDEN et al., 1997; HOGSETTE, 1999). Portanto, é necessário reduzir o uso desses produtos mediante o emprego de alternativas mais seguras de controle. Assim, os agentes de controle biológico são uma alternativa econômica e ecologicamente viável (VALADARES-INGLIS et al., 1998).

Os programas de controle integrado de pulgas devem ter como objetivo principal a redução das infestações a níveis toleráveis nos hospedeiros e no ambiente. Esses níveis são subjetivos e devem ser determinados com base nas características próprias a cada sistema de criação, em que se integram o hospedeiro, o parasito e o ambiente comum a ambos (DRYDEN, 1995). Segundo Carlotti e Jacobs (2000), o objetivo do controle sempre deve ser a eliminação total da população de pulgas dentro da casa. Esta meta não é fácil de atingir, já que esta pulga tem uma capacidade reprodutiva alta e um ciclo de vida complexo.

Atualmente há varias opções de organismos para o controle biológico, tais como insetos, nematóides, protozoários, bactérias, fungos e vírus (HOGSETTE, 1999). Segundo Alves (1998), fungos são patógenos capazes de infectar diferentes estágios de desenvolvimento dos hospedeiros, como ovos, larvas, pupas e adultos, sendo esta característica bastante desejável. Quando comparados com outros grupos de patógenos, os fungos levam uma certa vantagem, pois a maioria deles é altamente especializada na penetração via tegumento do inseto, diferente dos outros que só penetram via oral.

A penetração normal dos fungos é pelo tegumento, através de atividade enzimática ou pressão mecânica exercida pelo tubo germinativo e apressório. Os ciclos desta relação apresentam-se de um modo geral pelas fases de: adesão, germinação, formação de apressórios, formação de grampo de penetração, penetração, colonização e ainda, reprodução e disseminação do patógeno (ALVES, 1998).

Muitos fungos entomopatogênicos como Metarhizium anisopliae infectam a cutícula dos hospedeiros via conídios que se aderem e germinam formando uma série de estruturas durante a penetração (WANG; ST. LEGER, 2005). Esta espécie fúngica produz uma variedade de enzimas degradantes de cutícula durante a penetração no hospedeiro (ST. LEGER et al., 1991).

Metarhizium anisopliae infecta uma variedade de insetos, através da penetração direta da cutícula do hospedeiro. Explorando a base molecular desse processo, Freimoser et al. (2005) inspecionaram as respostas de expressão gênica para cutículas de diversos insetos. Este estudo demonstrou que essa espécie fúngica pode ajustar seus padrões de expressão gênica rapidamente, dando respostas específicas a cutículas diferentes.

A penetração fúngica no tegumento do inseto alvo seguido de colonização, infecção generalizada e posterior morte do inseto geralmente ocorre entre três a dez dias após contato. Este processo porém é dependente de fatores limitantes como componentes nutricionais da cutícula, reações químicas e ação de micotoxinas (CHANDLER et al., 2000).

O objetivo deste trabalho foi verificar e avaliar as diferentes fases de desenvolvimento dos fungos $M$. anisopliae e Beauveria bassiana sobre a cutícula de Ctenocephalides felis felis adultos, através do estudo das eletromicrografias obtidas em microscopia eletrônica de varredura.

As pulgas utilizadas nesse experimento foram obtidas de gatos mantidos na Estação para Pesquisas Parasitológicas W. O. Neitz do Departamento de Parasitologia Animal da UFRRJ. A colônia foi mantida segundo a metodologia de Santos (2000). Cada bioensaio foi composto de dois tratamentos, um na concentração $10^{8}$ conídios $/ \mathrm{ml}$, e um grupo controle para cada isolado, sendo um total de quatro tratamentos, para os quais foram feitas dez repetições, sendo que cada repetição foi constituída por cinco pulgas adultas.

Os isolados testados foram o M. anisopliae (Ma) 959 e $B$. bassiana (Bb) 986, nas respectivas concentrações, 2,2 e 2,4 x $10^{8}$ conídios/ml, onde cada tubo com pulgas recebeu um mililitro de suspensão fúngica a ser testada. As pulgas permaneceram imersas por três minutos, depois os tubos foram invertidos e o excesso de suspensão absorvido pelo algodão.

Para a observação do desenvolvimento do fungo sobre a cutícula, as pulgas foram fixadas em diferentes tempos após a infecção, sendo com duas, 15, 24 e 96 horas após o tratamento, o fixador utilizado foi o glutaraldeído 2,5 \%, em tampão de fosfato de potássio a 0,05M e ph 7,4 por 24 horas. Em seguida as amostras foram desidratadas, primeiramente em solução crescente de álcool etílico e água destilada por 15 minutos, depois em soluções crescentes de acetona em álcool etílico, também por 15 minutos.

A secagem das amostras foi obtida em ponto crítico, feito com dióxido de carbono e a metalização em ouro foi realizada por 240 segundos no aparelho BAL-TEC modelo SCD 050. O material metalizado foi observado em microscópio eletrônico de varredura Zeiss, modelo DSM 962.

Com a obtenção das eletromicrografias, observou-se que com duas horas após a infecção fúngica, os conídios estavam 

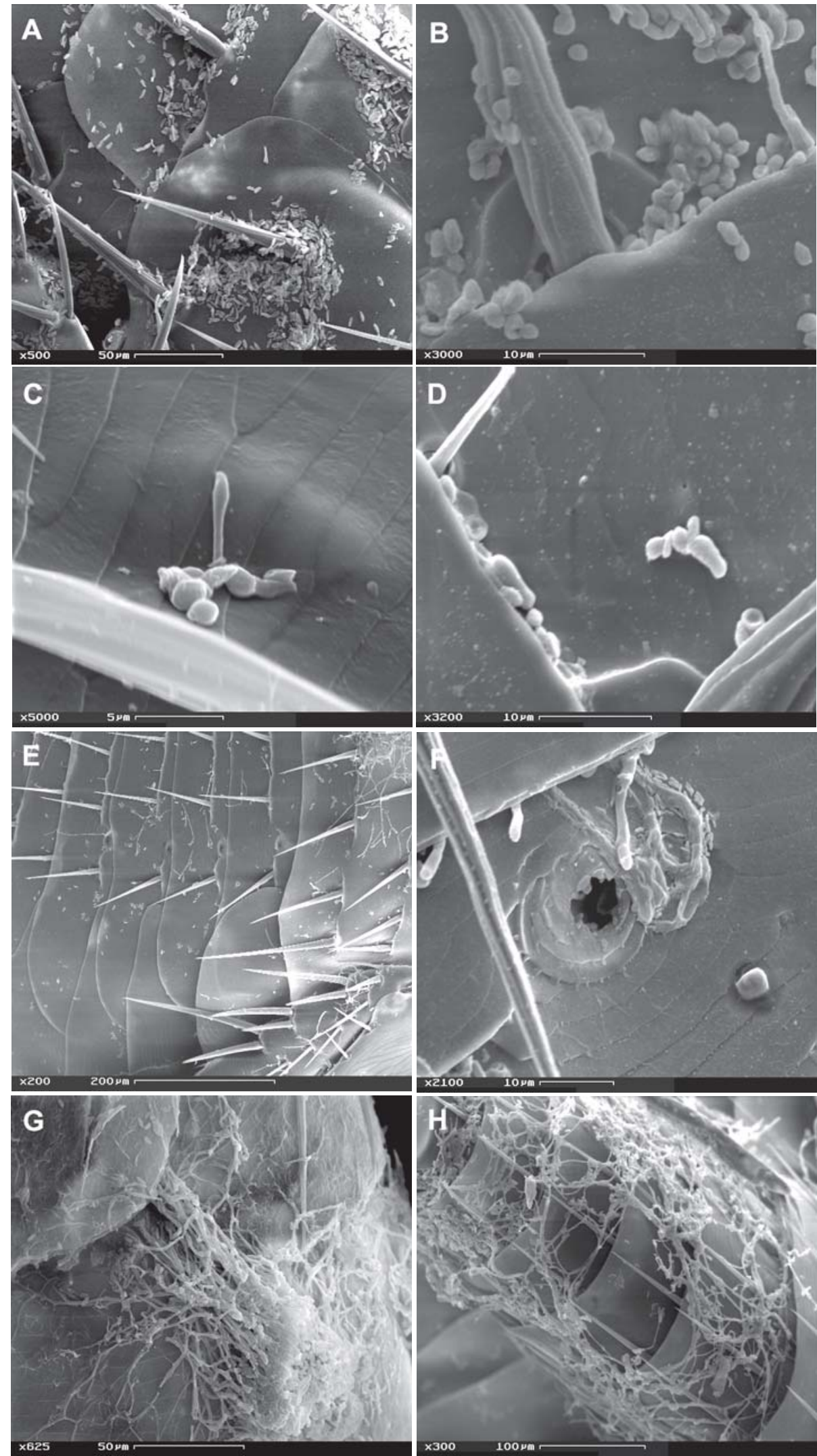

Figura 1. Eletromicrografias obtidas em microscópio eletrônico de varredura, demonstrando o desenvolvimento dos fungos Metarhizium anisopliae Ma 959 (A, C, E e G) e do fungo Beauveria bassiana Bb 986 (B, D, F e H) sobre a cutícula da pulga Ctenocephalides felis felis. A (Bar = 50 um) e B $($ Bar $=10 \mu \mathrm{m})$ - duas horas após infecção fúngica, demonstrando a adesão dos conídios a cutícula; C (Bar = $5 \mu \mathrm{m})$ e D (Bar = $10 \mu \mathrm{m})$ germinação dos conídios 15h após a infecção; E (Bar = $200 \mu \mathrm{m})$ e $\mathrm{F}(\mathrm{Bar}=10 \mu \mathrm{m})$ - crescimento e ramificação das hifas após 24h do tratamento; $\mathrm{G}(\mathrm{Bar}=50 \mu \mathrm{m})$ e H (Bar = $100 \mu \mathrm{m})$ - crescimento micelial, com a formação de colônia e conidiogênese, 96 horas após o tratamento. 
aderidos por toda a cutícula (Figura 1-A e B). Para avaliar o mecanismo de infecção da mesma espécie fúngica utilizada no presente trabalho, Garcia et al. (2004) infectaram fêmeas ingurgitadas do carrapato Rhipicephalus sanguineus, com o isolado Ma E9 e verificaram, através da microscopia eletrônica de varredura, a aderência de grande quantidade de conídios sobre a cutícula dos carrapatos uma hora após a infecção. Esse processo de adesão depende das enzimas esterases e proteases, que ocorrem na superfície dos conídios não germinados que alteram a superfície do tegumento do inseto, favorecendo a nutrição e a germinação do fungo (WANG; ST. LEGER, 2005).

Observou-se que com 15 horas após a infecção, para ambos fungos utilizados nesse experimento, houve a formação de tubos de germinação e de hifas sobre a cutícula da pulga, demonstrada na Figura 1 (C e D). Wraight et al. (1990) ao estudarem o processo de germinação de Erynia radicans sobre ninfas de Empoasca fabae observaram que o percentual de germinação não diferiu entre as regiões da cabeça, do tórax e do abdome, mas a porcentagem de conídios que deram origem as penetrações era de $5 \%$ depois de $10-12$ h e $20 \%$ depois de 48 h. Segundo St. Leger et al. (1991), na presença de nutrientes e níveis ideais de umidade, o fungo $M$. anisopliae forma tubos germinativos na superfície cuticular do hospedeiro, formando um apressório e logo após forma um grampo de penetração, que com o auxílio de enzimas penetra na epicutícula, estabelecendo uma relação nutricional com o hospedeiro. Também Bittencourt et al. (1999), através da microscopia eletrônica de varredura, demonstraram que a espécie fúngica M. anisopliae, isolado Ma 959, foi capaz de aderir, germinar e formar o apressório sobre a cutícula do carrapato Boophilus microplus. No presente trabalho não foi possível a observação do apressório e do grampo de penetração, no entanto, o fato do fungo desenvolver-se até a formação da colônia sugere que todas as etapas tenham sido realizadas pelo fungo.

O engrossamento e as ramificações das hifas de ambos os fungos foram os achados 24 horas após a infecção. Foi observado um maior número de hifas nas membranas intersegmentais do abdome da pulga, sugerindo que essa região seria o local de predileção para a penetração do fungo, como ilustrada na Figura 1 ( $\mathrm{E}$ e $\mathrm{F}$ ). Alguns autores citam que as membranas intersegmentais do abdome são mais comumente acometidas pelos fungos, porém espiráculos respiratórios, aparelho bucal, ânus e tarsos, também são locais de penetração fúngica (WRAIGHT et al.,1990, ST. LEGER, 1991, ALVES, 1998). De forma geral, cada grupo de patógeno possui um mecanismo específico para penetração. Tanto bactérias como os vírus, que predominam nas inoculações via oral, têm como barreira o micro-habitat intestinal, representado por reações enzímicas e pH que se constituem em fator supressivo desse patógeno (ALVES; LECUONA, 1998). Ainda, segundo afirmação de Alves (1998), a penetração normal dos fungos é via tegumento através de atividade enzimática ou pressão mecânica exercida pelo tubo germinativo e apressório.
Após 96 horas da infecção fúngica, observou-se (Figura 1 - G e H), o crescimento micelial, com a formação de colônia e a conidiogênese do fungo sobre a cutícula de $C$. $f$. felis. O desenvolvimento dos isolados fúngicos de $M$. anisopliae e $B$. bassiana, demonstram o potencial patogênico dessas espécies para promoverem o controle destes parasitas em ensaio in vitro.

Após observação das eletromicrografias, verificou-se que os isolados testados de M. anisopliae e B. bassiana completam seu ciclo sobre a cutícula da pulga C. f. felis. Os conídios de ambos fungos estudados estavam aderidos à cutícula com duas horas após a infecção, apresentaram germinação 15 horas após infecção e 96 horas após infecção verificou-se a conidiogênese dos fungos sobre a cutícula de C.f. felis.

Agradecimentos:- A Embrapa-Agrobiologia e a Universidade Estadual do Norte Fluminense Darcy Ribeiro, pela utilização dos equipamentos de microscopia eletrônica.

\section{REFERÊNCIAS BIBLIOGRÁFICAS}

ALVES, S. B. Controle Microbiano de Insetos. 2. ed. Piracicaba: FEALQ, 1998. 1163p.

ALVES, S. B; LECUONA, R. E. Epizootiologia aplicada ao controle microbiano. In: ALVES, S. B. Controle Microbiano de Insetos. 2. ed. Piracicaba: FEALQ, 1998. 1163p.

BITTENCOURT, V.R.E.P., MASCARENHAS, A.G.; FACCINI, J.L.H. Mecanismo de infecção do fungo Metarhizium anisopliae no carrapato Boophilus microplus em condições experimentais. Ciência Rural, v. 29, n. 2, p. 351-354, 1999.

BOSSARD, R. L.; HINKLE, N. C.; RUST, M. K. Review of inseticide resistance in cat fleas (Siphonaptera: Pulicidae). Journal of Medical Entomology, v. 35, n. 4, p. 415-422, 1998.

CARLOTTI, D. N.; JACOBS, D. E. Terapy, control and prevation of flea allergy dermatitis in dogs and cats. Veterinary Dermatology, v. 11, n. 1, p. 83, 2000.

CHANDLER, D.; DAVIDSON, G.; PELL, J. K.; BALL, B. V.; SHAW, K.; SUNDERLAND, K. D. Fungal biocontrol of acari. Biocontrol Science Technology, v. 10, n. 3, p. 357384, 2000.

DRYDEN, M. W.; BROCE, A. B. Development of trap for collecting newly emerged Ctenocephalides felis ( Siphonaptera:Pulicidae) in homes. Journal of Medical Entomology, v. 30, n. 5, p. 901-906, 1993.

DRYDEN, M. W.; PEREZ, H. R.; ULITCHNY, D. M. Efficacy of imidacloprid against Ctenocephalides felis in dogs and cats under field conditions. In: THE BAYER INTERNATIONAL FLEA CONTROL SYMPOSIUM, 1, 1997, Birningham. Proccedings...Birningham: Bayer, 1997. p. 5-10.

DRYDEN, M.W. Management of flea infestations. In: CONGRESS OF THE WORLD VETERINARY ASSOCIATION, 25, 1995, Yokohama. Proccedings... Yokohama: WVA, 1995. p. 308-313. 
FREIMOSER, F. M.; G. HU; R. J. St. LEGER. Variation in gene expression patterns as the insect pathogen Metarhizium anisopliae adapts to different host cuticle or nutrient deprivation in vitro. Microbiology, v. 151, n. 3, p. 361-371, 2005.

GARCIA, M. V.; MONTEIRO, A.C.; SZABÓ, M.P.J. Colonização e lesão em fêmeas ingurgitadas de carrapato Rhipicephalus sanguineus causadas pelo fungo Metarhizium anisopliae. Ciência Rural, v. 34, n. 5, p. 15131518, 2004.

HOGSETTE, J. A. Management of ectoparasites with biological control. International Journal for Parasitology, v. 29, n. 1, p. 147-151, 1999.

LINARDI, P. M.; GUIMARÃES , L. R. Sifonápteros do Brasil. São Paulo: Museu de Zoologia, USP/FAPESP. 2000, 291p.

SANTOS, H. D. Período de desenvolvimento dos estágios imaturos de Ctenocephalides felis felis (Bouché, 1835) (Siphonaptera:Pulicidae) mantidos em condições controladas e no ambiente. 2000. 67f. Dissertação (Mestrado)
Universidade Federal Rural do Rio de Janeiro, Seropédica, 2002.

ST LEGER, R. J.; GOETTEL, M.; ROBERTS, D. W.; STAPLES, R. C. Penetration events during infection of host cuticle by Metarhizium anisopliae. Journal of Invertebrate Pathology, v. 58, n. 1, p. 168-170, 1991.

VALADARES-INGLIS, M. C. C.; SHILER, W.; SOUZA, M. T. Engenharia genética de microrganismos agentes de controle biológico. In: MELO, I. S.; AZEVEDO, J. L. Controle Biológico. Jaguariúna: Embrapa-CNPMA, 1998. v. 1, p. 201-230.

WANG, C; ST. LEGER, R. J. Developmental and transcriptional responses to host and nonhost cuticles by the specific locust pathogen Metarhizium anisopliae var. acridum. Eukaryotic Cell, v. 4, n. 5, p. 937-947, 2005.

WRAIGHT, S.; BUTT, P.T.M.; GALAINI, S.; ALLE, L. L.; SOPER, R. S.; ROBERTS, D.W. Germination and infection processes of the entomophthoralean fungus Erynia radicans on the potato leafhopper, Empoasca fabae. Journal of Invertebrate Pathology, v. 56, n. 2, p. 157-174, 1990.

Recebido em 20 de julho de 2006.

Aceito para publicação em 15 de julho de 2007. 